\title{
Transformational Leadership In Hierarchical Context: A Study Of Gender Differences In The Mobile Communication Sector In Egypt
}

Abdel Moneim Elsaid, Ain Shams University, Egypt

Basant N.S. Mostafa, Future University in Egypt, Cairo, Egypt

\begin{abstract}
This paper empirically studies leaders' gender differences in transformational leadership among both lower and middle level managers while examining the difference between lower and middle level mangers regarding transformational leadership behaviors. A sample of 122 managers from all three Mobile service providers (Mobinil, Vodafone, and Etisalat) currently operating in Egypt are studied. Transformational leadership was measured through five behaviors using the Bass and Avolio (1997) Multifactor Leadership Questionnaire. Leaders self-rated their transformational leadership behaviors. Results showed that there is no significant difference between lower and middle managerial levels in all transformational leadership behaviors. Female lower level managers did not excel significantly in all transformational leadership behaviors. However they exceled only in the idealized attribute dimension while no significant difference between male and female middle level managers was found.
\end{abstract}

Keywords: Gender; Egypt; Mobile Communications; Transformational Leadership

\section{INTRODUCTION}

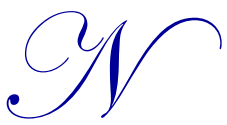

owadays changes in business, technology and social environments are constantly affecting organizational functioning. Leadership is seen as the core spirit to proactively shape the future of organizations (Voon et al., 2010). Over the past 30 years, transformational leadership has become one of the most important theories of organizational behavior; its uniqueness emerged from directing and inspiring employees' efforts by raising their awareness of the importance of organizational values and outcomes in contrast to other leadership styles that are based on individual gain and the exchange of rewards (Wright et al., 2012).

Recently, the adoption of transformational leadership has gained significant interest from management researchers as it could change employees' behaviors through conscious and unconscious learning processes that are based on employees' cognitive and emotive maps (Nwokah, 2008).The popular stereotyping among gender and promoting males as leaders among traditional societies is on its way to be changed as the percentage of female leaders is gradually increasing taking into consideration that male leaders are still dominating most of the managerial positions (Judeh, 2010; Verma and Krishnan, 2013). Previous studies (Manning, 2002; Judeh, 2010; Zeinabadi, 2013) have been conducted to study transformational leadership and gender difference among each of its attributes and have yielded contradictory results. This stimulated the thinking to go beyond gender differences and consider one more contextual aspect which is the hierarchical level. This view was supported in the work of Kent et al., (2010).

This paper's main contribution is to further our understanding of the contextual impact of hierarchical level on transformational leadership. In turn, this will help shed some light on a new and exciting area of research, especially in the Egyptian context where it has not been investigated to date. The main objective of this study is to show how transformational leadership behaviors differ between lower and middle level managers along with investigating leaders' gender differences among each of them utilizing the five attributes of transformational leadership. 


\section{THEORETICAL BACKGROUND}

\section{Transformational Leadership}

Transformational Leadership theory was developed by Burns (1978), he laid the foundation of this theory and then it was enhanced by Bernard Bass and Bruce Avolio from 1985 to 1998, after that it caught the interest of many researchers over the past few years (Givens, 2008). Transformational leadership can be considered as the act of moving the followers beyond immediate self-interests through charisma, inspiration, intellectual stimulation or individualized consideration, which elevates the followers' level of maturity, concern for achievements, selfactualization and the well-being of others, the organization and the society (Bass, 1999). These components can be utilized by managers to face organizational uncertainty and instability (Hinkin and Tracey, 1999).

Avolio and Bass (1995) perceived transformational leaders to be those leaders who inspire their followers to consider the desired organizational goals as their own causes and views. A similar point of view to the former demonstrated that the higher purpose that is entailed from transformational leadership is to synchronize the aims and aspirations of leaders with those of the followers (Lian and Tui, 2012). Kuhnert and Lewis (1987) considered transformational leadership to be achieved when a leader's end values are followed by subordinates and consequently influences the attitudes, beliefs and goals of their followers. Kanungo (2001) supported the prior influencing idea; however he emphasized that this influencing process is an ethical influencing process when applying transformational leadership, as it uses employee empowerment strategies to enhance employee self-worth rather than controlling ones so that, employees can see the organization's vision as a reflection of their own values rather than as an outside imposition.

Different studies supported the positive impact of transformational leaders' behavior. Ghafoor et al., (2011) concluded that the transformational leadership style has a positive effect in supporting the development of employees' identity and consequently reducing their intentions to quit. Voon et al., (2010) demonstrated that transformational leadership with its positive relationship with job satisfaction could improve employees' as well as organizational performance as a whole. Bass (1995) found that some employees' competencies as well as the leaderemployee relationship could be highly enhanced when applying transformational leadership. The enhanced interpersonal relationship between supervisor and subordinate that resulted from applying transformational leadership could help employees become more creative, innovative and could stimulate their competitive thinking about new ideas for organizational growth and adaptation to the outside dynamic environment (Bushra et al., 2011).

The discussion about transformational leadership is underlying the ethical consideration of not only avoiding wronging the staff, but also of having the intention to do right by them (Parry and Proctor-Thomson, 2002). Transformational leaders could be good or bad and the main factor that differentiates good transformational leaders from bad ones is the degree by which leaders prioritize the interest of their subordinates over their self-interest (Hoption et al., 2013).The ethical dimension of transformational leadership incorporates the follower's values and the leader to a higher realm of motivation and ethics ( $\mathrm{Bi}$ et al., 2012).Transformational leadership is a popular leadership style in resolving ethical issues as transformational leaders serve as role models of ethical behaviors through focusing on employees' moral development which creates a positive culture within the entire organization (Odom and Green, 2003).

\section{Transformational Leadership Dimensions}

Transformational leadership is globally accepted across different nations because of its popularity in developing employees who perform beyond expectations (Lievens et al., 1997; Boehnke et al., 2003). There are five important leader behaviors that represent the dimensions of transformational leadership. Among them, idealized influence is considered to be the largest component (Bass, 1995).

\section{Idealized Influence Attribute (Charisma)}

Transformational leaders are famous for having charismatic features. They have the ability to create emotional bonds between themselves and their employees, through which they project their sense of power, confidence and 
dynamism into their team members and at the same time, promoting high expectations from their employees in achieving organizational goals (Pastor and Mayo, 2008). These charismatic leaders are perceived by their employees as highly ethical, respected, admired and trusted leaders (Fernando et al., 2009).

\section{Idealized Influence Behaviors}

According to Bass and Avolio (1993) as cited in Simic (1998): "Leaders who possess idealized influence behaviors do not use their leadership position and abilities to achieve personal interests, but they direct them to use the potentials of their followers to achieve the aims of organizations." Transformational leaders are goal oriented as their actions are based on the organizational values and principles in a way that they consider the needs of their employees and rate them over their own personal needs (Fernando et al., 2009).

\section{Inspirational Motivation}

Inspirational motivation goes beyond mere motivation; the later focuses mainly on providing incentives to employees to get the best out of them however, inspirational motivation leads to a significant difference in employees' attitudes through devoting them to the attractive future states for the organization (Jackson, 2012). Transformational leaders are known to be inspirational leaders; along with communicating clear standards, goals and expectations about effectiveness, efforts and commitment, they also provide meaning to organizational goals through displaying enthusiasm and optimism to their employees in a simple language and using symbolism (Pastor and Mayo, 2008).

\section{Intellectual Stimulation}

Transformational leaders always possess an encouragement behavior through which they mentally stimulate their employees to take the initiative to deal with old problems using new solution and approaches (Voon et al., 2010). Intellectual stimulation refers to the behavior of transformational leaders who stimulate creativity in their employees, help them to reframe problems in new ways and they never criticize individual members' mistakes (Pastor and Mayo, 2008).

\section{Individualized Consideration}

Transformational leaders have an individualized view of each of their employees; they usually consider their employees' individual needs and requirements for achievement, growth and development (Rohmann and Rowold, 2009). Leaders, according to this behavior always accept individuals' differences through involving each employee in a suitable challenging task (Pastor and Mayo, 2008).

\section{Transformational Leadership, Hierarchical Levels and the Role of Gender}

Previous research on the cross-hierarchical differences in transformational leadership is scarce; especially studies that incorporate more than one managerial level (Bruch and Walter, 2007). The effectiveness of adopting transformational leadership was found to be the same across different hierarchical levels; however different hierarchical levels may not equally possess all behaviors of transformational leadership (Edwards and Gill, 2012). The higher the hierarchical level, the broader its context for transformational leadership behavior (Bruch and Walter, 2007).

Upper managerial levels are frequently characterized as being more charismatic and inspirational than middle managers. Both managerial levels equally possess intellectual stimulation and individualized consideration. Also, the former characteristics in addition to intellectual stimulation can be more effective in enhancing employees' job satisfaction when delivered by upper managers towards middle managers than when delivered by middle managers towards first-line supervisors (Bruch and Walter, 2007).

Hypothesis 1: There is no significant difference in the effectiveness of transformational leadership behaviors between the lower managerial level and the mid-managerial level. 
Gender is found to be one of the characteristics that affect how male and female leaders behave differently. A recent study challenged the conventional wisdom that leadership is highly attributed to males rather than females when it concluded that more benefits are associated with having transformational female leaders than male ones, in a way that females show more outcomes of social exchange (Zeinabadi, 2013). Women always prefer transformational leadership than any other leadership style; they excel in its five behavioral components especially for individualized consideration (Schyns et al., 2008). Yaseen (2010) concluded that women in the Arab world are excelling more on transformational leadership scales than men. For idealized influence, Arab female leaders are building respect when they go beyond self-interest for the good of the group. For inspirational motivation, Arab female leaders are optimistically expressing confidence in achieving the organizational vision by being enthusiastic about the required actions. For intellectual stimulation, they check the critical assumptions to solve a problem. For individualized consideration; they spend coaching and assessing times to develop their employees' strength. Synchronizing the former point of view with the hierarchical context fueled the second and third hypothesis of our research paper.

Hypothesis 2: In the lower managerial level, female leaders significantly excel in all transformational leadership behaviors when compared to their male counterparts.

Hypothesis 3: In the mid-managerial level, female leaders significantly excel in all transformational leadership behaviors when compared to their male counterparts.

\section{METHODOLOGY}

\section{Data Collection and Measuring Instrument}

The required data for this paper was collected through the Multifactor Leadership Questionnaire (MLQ) of Bass and Avolio (1997) who identified this scale as an appropriate, reliable scale for measuring transformational leadership. Most of the research on transformational leadership has used the Multifactor Leadership Questionnaire (Hayward et al., 2008; Xirasagar, 2008; Hinkin and Tracey, 1999). Leaders assessed their leadership behaviors using 5 Likert's scale from 0 to 4, where 0 indicates a "not at all" and 4 indicates a "frequently if not always". The collected data for all transformational leadership dimensions was scanned for normality and skewness tests before performing statistical analysis and it was found to be between -1.96 and +1.96 , which indicated that data was normally distributed. Confirming the reliability of the Multifactor Leadership Questionnaire (MLQ), Cronbach's alphas were checked in the five dimensions and were found to be satisfactory as follows: idealized influence attribute (0.885); idealized influence behavior (0.903); inspirational motivation (0.899); intellectual stimulation (0.904); individualized consideration (0.887) and alpha for all dimensions was (0.915).

\section{Sample and Procedure}

A sample of 130 participants from all of the three mobile communication service providers in Egypt agreed to participate in this study. These organizations have relatively well-defined hierarchical structure. Consequently, in addition to the Multifactor Leadership Questionnaire, a self-report question was used to capture respondents' hierarchical level, as it is most common in organizational research (Bruch and Walter, 2007). Multifactor Leadership Questionnaires were administered to both lower-level and mid-level managers to describe their leadership styles. A total of 122 filled-out questionnaires were collected representing a rate of $94.8 \%$ of total distributed questionnaires.

\section{RESULTS}

For the lower level managers, 70 questionnaires were filled-out, of which $57.4 \%$ are males and $42.6 \%$ are females. For the mid-level managers, 52 questionnaires were filled out, of which $51 \%$ are males and are $49 \%$ females. Descriptive statistics and correlations of transformational leadership behaviors are reported in Table 1 below: 
Table 1. Descriptive statistics and correlations of transformational leadership behaviors

\begin{tabular}{lccccccc}
\hline \multicolumn{1}{c}{ Dimensions } & Mean & Std. Deviation & $\mathbf{1}$ & $\mathbf{2}$ & $\mathbf{3}$ & $\mathbf{4}$ & $\mathbf{5}$ \\
\hline Idealized Behavior & 0.1208 & 0.27391 & & 0.628 & 0.711 & 0.551 & 0.751 \\
Idealized Attribute & 0.0287 & 0.33555 & 0.628 & & 0.788 & 0.792 & 0.667 \\
Individualized Consideration & 0.0384 & 0.32476 & 0.711 & 0.788 & & 0.73 & 0.627 \\
Inspirational Motivation & 0.0988 & 0.30594 & 0.551 & 0.792 & 0.73 & & 0.593 \\
Intellectual Stimulation & 0.0822 & 0.31512 & 0.751 & 0.667 & 0.627 & 0.593 & \\
\hline
\end{tabular}

Correlation is significant at the 0.05 level (2-tailed)

Table 1 shows that idealized attribute has the lowest mean $(0.0287)$ with a standard deviation of $(0.3355)$ and the highest mean was for idealized behavior (0.1208) with standard deviation of (0.27391). Table 2 below shows the means, standard deviations and mean differences of lower and mid-level managers' ratings regarding the five dimensions. Mid-level managers were evaluated to be more effective than lower level managers in all dimensions of transformational leadership behavior except for intellectual stimulation where lower level managers were evaluated with a slightly higher score and for individualized consideration; both managerial levels are approximately equal.

Table 2. Comparison of lower and mid-level managers' means and standard deviations of ratings

\begin{tabular}{l|l|l|c|c}
\hline \multicolumn{1}{c}{ Dimensions } & \multicolumn{1}{c}{ Hierarchy } & Mean & Std. Deviation & Mean Difference \\
\hline \multirow{2}{*}{ Idealized Behavior } & Lower Level & 0.1462 & 0.26793 & -0.67 \\
& Mid-Level & 0.82 & 0.28531 & -0.0586 \\
\hline \multirow{2}{*}{ Idealized Attribute } & Lower Level & 0.002 & 0.35515 & 0.31058 \\
& Mid-Level & 0.0606 & 0.32962 & \multirow{2}{*}{-0.001} \\
\hline \multirow{2}{*}{ Individualized Consideration } & Lower Level & 0.0374 & 0.32087 & \multirow{2}{*}{-0.0347} \\
& Mid-Level & 0.0383 & 0.32556 & \multirow{2}{*}{0.0441} \\
\hline \multirow{2}{*}{ Inspirational Motivation } & Lower Level & 0.0844 & 0.28002 & 0.30778 \\
\hline \multirow{2}{*}{ Intellectual Stimulation } & Mid-Level & 0.1045 & 0.32418 & \\
\hline
\end{tabular}

Tables 3 and 4, show the means, standard deviations and mean differences of male and female ratings in both managerial levels regarding the five dimensions. It was found that female lower-level managers were more effective than their male counterparts in all dimensions of transformational leadership behavior. On the other hand, female mid-level managers were found to be more effective than their male counterparts in idealized attribute, individualized consideration and inspirational motivation. Male mid-level managers scored higher than their female counterparts on idealized behavior and intellectual stimulation.

Table 3. Comparison of male and female lower-level managers' means and standard deviations of ratings

\begin{tabular}{l|l|c|c|c}
\hline \multicolumn{1}{c|}{ Dimensions } & \multicolumn{1}{c|}{ Gender } & Mean & Std. Deviation & Mean Difference \\
\hline \multirow{2}{*}{ Idealized Behavior } & Male & 0.1007 & 0.26383 & -0.1043 \\
& Female & 0.205 & 0.26274 & -0.179 \\
\hline \multirow{2}{*}{ Idealized Attribute } & Male & -0.0743 & 0.35545 & 0.32717 \\
\hline \multirow{2}{*}{ Individualized Consideration } & Female & -0.01047 & 0.331 & -0.1246 \\
\hline \multirow{2}{*}{ Inspirational Motivation } & Female & 0.112 & 0.31407 & -0.1349 \\
\hline \multirow{2}{*}{ Intellectual Stimulation } & Male & 0.0284 & 0.32568 & 0.30806 \\
& Female & 0.1633 & 0.30799 & \multirow{2}{*}{-0.0947} \\
\hline
\end{tabular}


Table 4. Comparison of male and female mid-level managers' means and standard deviations of ratings

\begin{tabular}{l|l|c|c|c}
\hline \multicolumn{1}{c|}{ Dimensions } & \multicolumn{1}{c|}{ Gender } & Mean & Std. Deviation & Mean Difference \\
\hline \multirow{2}{*}{ Idealized Behavior } & Male & 0.1011 & 0.26901 & 0.0398 \\
& Female & 0.0613 & 0.30588 & \multirow{2}{*}{0.1401} \\
\hline \multirow{2}{*}{ Idealized Attribute } & Male & 0.0069 & 0.33577 & 0.26863 \\
\hline \multirow{2}{*}{ Individualized Consideration } & Female & 0.0102 & 0.32811 & -0.0583 \\
& Female & 0.0685 & 0.31649 & \multirow{2}{*}{0.0803} \\
\hline \multirow{2}{*}{ Inspirational Motivation } & Male & 0.0804 & 0.27829 & 0.28128 \\
\hline \multirow{2}{*}{ Intellectual Stimulation } & Female & 0.075 & 0.32425 & \multirow{2}{*}{0.0304} \\
& Male & 0.0446 & 0.32977 & \\
\hline
\end{tabular}

Independent sample t-tests were used to examine whether there are significant differences between lower managerial level and mid-managerial level in the five behaviors of transformational leadership based on self-ratings. Also, they were utilized to investigate the significant differences between male and female managers in each of the former managerial levels. Table 5 shows the results of independent sample t-tests for the studied hierarchical levels:

Table 5. Results of independent sample t-tests (for lower managerial level and mid-managerial level)

\begin{tabular}{l|c|c|c|c|c}
\hline \multirow{2}{*}{\multicolumn{1}{c|}{ Dimensions }} & \multicolumn{2}{|c|}{$\begin{array}{c}\text { Levene's Test for Equality of } \\
\text { Variances }\end{array}$} & Sig. & t & \multicolumn{2}{|c}{ df } & sig. (2-tailed) \\
\cline { 2 - 6 } & F & 0.441 & 1.29 & 123 & 0.199 \\
Idealized Behavior & 0.598 & 0.229 & -0.963 & 123 & 0.337 \\
Idealized Attribute & 1.465 & 0.141 & 0.708 & -0.014 & 123 \\
Individualized Consideration & 0.141 & 0.163 & -0.626 & 123 & 0.533 \\
Inspirational Motivation & 1.969 & 0.669 & -0.773 & 123 & 0.441 \\
Intellectual Stimulation & 0.183 & &
\end{tabular}

Table 5 indicates that there is no significant difference between lower managerial level and mid-managerial level in all of the five transformational leadership behaviors. Levene's test was used to verify the equality of variances and the $\mathrm{P}$ - value is $(\mathrm{P}>0.05)$ for each of the five dimensions and reflected that the null hypothesis of homogeneity of variances has been achieved. Table 6 shows the results of independent sample t-tests for male and female lower level managers:

Table 6. Results of independent Samples t-test for lower level male and female managers

\begin{tabular}{|c|c|c|c|c|c|}
\hline \multirow[t]{2}{*}{ Dimensions } & \multicolumn{2}{|c|}{$\begin{array}{c}\text { Levene's Test for Equality } \\
\text { of Variances }\end{array}$} & \multicolumn{3}{|c|}{ t- test for Equality of Means } \\
\hline & $\mathbf{F}$ & Sig. & $\mathbf{t}$ & df & sig. (2-tailed) \\
\hline Idealized Behavior & 0.309 & 0.58 & -1.656 & 70 & 0.102 \\
\hline Idealized Attribute & 0.061 & 0.805 & -2.176 & 70 & 0.033 \\
\hline Individualized Consideration & 0.086 & 0.77 & -1.609 & 70 & 0.112 \\
\hline Inspirational Motivation & 0.202 & 0.654 & -1.772 & 70 & 0.081 \\
\hline Intellectual Stimulation & 0.121 & 0.729 & -1.281 & 70 & 0.204 \\
\hline
\end{tabular}

Table 6 confirms the null hypothesis of homogeneity of variances as the P- value is $(\mathrm{P}>0.05)$ for each of the five dimensions of transformational leadership. Furthermore, there was a significant difference between male and female lower level managers only on idealized attribute. There is no significant difference between male and female lower managers regarding the other four transformational leadership dimension. Table 7 shows the results of independent sample t-tests for male and female mid-level managers: 
Table 7. Results of independent sample t-tests for mid-level male and female managers

\begin{tabular}{l|c|c|c|c|c}
\hline \multirow{2}{*}{\multicolumn{1}{c|}{ Dimensions }} & \multicolumn{2}{|c|}{$\begin{array}{c}\text { Levene's Test for Equality of } \\
\text { Variances }\end{array}$} & \multicolumn{3}{c}{ t- test for Equality of Means } \\
\cline { 2 - 6 } & $\mathbf{F}$ & Sig. & $\mathbf{t}$ & df & sig. (2-tailed) \\
\hline Idealized Behavior & 1.202 & 0.278 & 0.508 & 52 & 0.613 \\
Idealized Attribute & 2.301 & 0.135 & -1.684 & 52 & 0.098 \\
Individualized Consideration & 0 & 0.989 & -0.664 & 52 & 0.51 \\
Inspirational Motivation & 0.147 & 0.703 & -1.054 & 52 & 0.297 \\
Intellectual Stimulation & 0.062 & 0.804 & 0.342 & 52 & 0.734 \\
\hline
\end{tabular}

Table 7 indicates that there no significant difference between males and females mid- level managers in all of the five transformational leadership behaviors. Also, variances were found to be equal as the $\mathrm{P}$ - value is $(\mathrm{P}>0.05)$ for each of the five dimensions and this reflected that the null hypothesis of homogeneity of variances has been achieved.

\section{CONCLUSION AND DISCUSSION}

This research paper studied the differences in transformational leadership behaviors between lower and midmanagerial levels along with gender differences in each managerial level regarding these behaviors. Mid-level managers were evaluated to be slightly more effective than lower level managers in three behaviors of transformational leadership; idealized behavior, idealized attribute and inspirational motivation. Lower level managers were found to be slightly more effective in intellectual stimulation. However, the results did not support any significant difference between lower and mid-managerial levels in all transformational leadership behaviors.

For lower managerial level, although female managers were found to be slightly more effective than male managers in all transformational leadership behaviors, no significant difference was found between male and female managers' transformational leadership behaviors except for idealized attribute where female leaders scored higher. For mid-managerial level, although female managers were found to be slightly more effective than male managers in idealized attribute, individualized consideration and inspirational motivation and male managers were evaluated to be slightly more effective in idealized influence and intellectual stimulation, these differences were found to be not significant. These findings are consistent with Judeh (2010) who concluded that there is no significant differences in transformational leadership behaviors between male and female managers at the same managerial levels.

Thus, the overall results indicate that there is no significant difference between lower and mid-managerial levels in all transformational leadership behaviors. Therefore, Hypothesis 1 is accepted. There is no significant gender difference in transformational leadership behaviors in each of the studied managerial levels except that female lower level managers excel in idealized attribute more than their male counterparts. This leads to the rejection of Hypothesis 2 and Hypothesis 3, as female lower level managers did not significantly excel in all transformational leadership behaviors.

\section{Future Research}

An interesting area for future research is to replicate our study in firms in different sectors in Egypt. It would be interesting to see if the results change depending on the kind of industry or stay the same. In addition, it would be interesting to examine whether the respondents' cultural background affects how they answer the Bass and Avolio (1997) Multifactor Leadership Questionnaire. Would we get the same results if we conducted our study in three firms in the mobile communication sector in the United States of America or in Canada?

\section{Limitations}

The sample is limited to lower and mid-managerial levels in Egypt. A sample of upper level managers, such as CEOs, CFOs and COOs would have provided interesting results. However, the response rate would have been low. The sample is also limited to lower and middle managers in the mobile communication sector. These results cannot necessarily be generalized to other sectors/industries. 


\title{
AUTHOR BIOGRAPHIES
}

\begin{abstract}
Abdel Moneim Elsaid received his Ph.D. from Southern Illinois University, Carbondale. He is an associate professor at the Faculty of Commerce, Ain Shams University, Cairo, Egypt. He has more than 12 years of practical experience both in Egypt and USA. His research interests include: female leadership, social loafing, cross-cultural studies and individual contribution and perception. He has published in Research \& Practice in Human Resource Management, Group Dynamics, Gender in Management: An International Journal and International Journal of Electronic Marketing and Retailing.
\end{abstract}

Basant N.S. Mostafa received her Bachelors' degree in Business Administration in 2008 from the Faculty of Commerce, Ain Shams University. She started her academic career as a TA in Future University in Egypt in 2011. She earned her Masters' degree from Ain Shams University in Human Resource Management in 2015. She has 2 years of practical experience in a multinational organization.

\section{REFERENCES}

Avolio, B., \& Bass, B. (1995). Individual consideration viewed at multiple levels of analysis: a multi-level framework for examining the diffusion of transformational leadership. The Leadership Quarterly, 6, 199-218.

Bass, B. (1995). Theory of transformational leadership redux. The Leadership Quarterly, 6, 463-478.

Bass, B., \& Avolio, B. (1997). Full range leadership development: manual for the multifactorleadership questionnaire. CA: Mind Garden.

Bass, B. (1999). Two decades of research and development in transformational leadership. European Journal of Work and Organizational Psychology, 8, 9-32.

Boehnke, K., Bontis, N., DiStefano, J., \& DiStefano, A. (2003). Transformational leadership: anexamination of cross-national differences and similarities. Leadership and Organization Development Journal, 24, 5-15.

Bruch, H., \& Walter, F. (2007). Leadership in context: investigating hierarchical impacts on transformational leadership. Leadership \& Organization Development Journal, 28, 710-726.

Bushra, F., Usman, A., \& Naveed, A. (2011). Effect of transformational leadership on employees' job satisfaction and organizational commitment in banking sector of Lahore (Pakistan). International Journal of Business and Social Science, 2, 261-267.

Edwards, G., \& Gill, R. (2012). Transformational leadership across hierarchical levels in UK manufacturing organizations. Leadership \& Organization Development Journal, 33, 25-50.

Fernando, M., Beal, F., \& Geroy, G. (2009). The spiritual dimension in leadership at Dilmah Tea. Leadership \& Organization Development Journal, 30, 522-539.

Ghafoor, A., Qureshi, T., Khan, M., \& Hijazi, S. (2011). Transformational leadership, employee engagement and performance: mediating effect of psychological ownership. African Journal of Business Management, 5, 7391-7403.

Givens, R. (2008). Transformational leadership: the impact on organizational and personal outcomes. Emerging Leadership Journeys, 1, 4-24.

Hayward, B., Baxter, J. \& Amos, T. (2008). Relationship between employee performance, leadership style and emotional intelligence: an exploratory study in a South African parastatal. Independent Research Journal in the Management Sciences, 8, 15-26.

Hinkin, T., \& Tracey, J. (1999). The relevance of charisma for transformational leadership in stable organizations. Journal of Organizational Change Management, 12, 105-119.

Hoption, C., Barling, J., \& Turner, N. (2013). It's not you, it's me: transformational leadership and self-deprecating humor. Leadership \& Organization Development Journal, 34, 4-19.

Jackson, B. (2012). Give your people a cause and inspiration will follow. Human Resource Management International Digest, 20 , 32-34.

Judeh, M. (2010). Transformational leadership style: a study of gender differences in private universities. International Review of Business Research Papers, 6, 118-125.

Kent, T., Blaire, C., Rudd, H., \& Schuele, U. (2010). Gender differences and transformational leadership behavior: do both German men and women lead in the same way? International Journal of Leadership Studies, 6, 52-66.

Kanungo, R. (2001). Ethical values of transactional and transformational leaders. Canadian Journal of Administrative Sciences, $18,257-265$.

Kuhnert, K., \& Lewis, P. (1987). Transactional and transformational leadership: a constructive developmental analysis. Academy of Management Review, 12, 648-657.

Bi, L., Ehrich, J., \& Ehrich, L. (2012). Confucius as transformational leader: lessons for ESL leadership. International Journal of Educational Management, 26, 391-402. 
Lian, L., \& Tui, L. (2012). Leadership styles and organizational citizenship behavior: the mediating effect of subordinates' competence and downward influence tactics. Journal of Applied Business and Economics, 13, 59-96.

Lievens, F., Geit, P., \& Coetsier, P. (1997). Identification of transformational leadership qualities: an examination of potential biases. European Journal of Work and Organizational Psychology, 6, 415-430.

Manning, T. (2002). Gender, managerial level, transformational leadership and work satisfaction. Women in Management Review, 17, 207-216.

Nwokah, N. (2008). Marketing in governance: leader-managerial practices for efficiency in competency-based administration and transformational marketing model. Corporate Governance, 8, 18-27.

Odom, L., \& Green, M. (2003). Law and the ethics of transformational leadership. Leadership and Organization Development Journal, 24, 62-69.

Parry, K., \& Proctor-Thomson, S. (2002). Perceived integrity of transformational leaders in organizational settings. Journal of Business Ethics, 35, 75-96.

Pastor, J., \& Mayo, M. (2008). Transformational leadership among Spanish upper echelons: the role of managerial values and goal orientation. Leadership \& Organization Development Journal, 29, 340-358.

Rohmann, A., \& Rowold, J. (2009). Gender and leadership style: a field study in differentorganizational contexts in Germany. Equal Opportunities International, 28, 545-560.

Schyns, B., Elverfeldt, A., \& Felfe, J. (2008). Is there a male advantage in the effects of feedback and leadership on leaders' occupational self-efficacy? Equal Opportunities International, 27, 596- 612.

Simic, I. (1998). Transformational leadership: the key to successful management of transformational organizational changes. The Scientific Journal, 1, 49-55.

Verma, S., \& Krishnan, V. (2013). Transformational leadership and follower's organizational commitment: role of leader's gender. NMIMS Management Review, 23, 91-112.

Voon, M., Lo, M., Ngui, K., \& Ayob, N. (2010). The influence of leadership styles on employees' job satisfaction in public sector organizations in Malaysia. International Journal of Business, Management and Social Sciences, 2, 24-32.

Wright, B., Moynihan, D., \& Pandey, S. (2012). Pulling the levers: transformational leadership, public service motivation, and mission valence. Public Administration Review, 72, 206-215.

Xirasagar, S. (2008). Transformational, transactional and laissez-faire leadership among physician executives. Journal of Health Organization and Management, 22, 599-613.

Yaseen, Z. (2010). Leadership styles of men and women in the Arab World. Education, Business and Society: Contemporary Middle Eastern Issues, 3, 63-70.

Zeinabadi, H. (2013). Social exchange outcomes of transformational leadership: comparing male and female principals of public primary schools in Iran. International Journal of Educational Management, 27, 730-74 


\section{APPENDECIES}

Appendix A: MLQ scoring key

\begin{tabular}{|l|l|l|l|l|l|l|}
\hline Description & Leadership Factors & Raw Factors & Q\# & Q\# & Q\# & Q\# \\
\hline & Transformational & Idealized Attributes & 10 & 18 & 21 & 25 \\
\hline & Transformational & Idealized Behaviors & 6 & 14 & 23 & 34 \\
\hline & Transformational & Inspirational Motivation & 9 & 13 & 26 & 36 \\
\hline & Transformational & Intellectual Stimulation & 2 & 8 & 30 & 32 \\
\hline & Transformational & Individualized Consideration & 15 & 19 & 29 & 31 \\
\hline
\end{tabular}

Where Q\# = Question Number 


\section{Appendix B: MLQ Leader Questionnaire and Answer Sheet}

Directions: This questionnaire is designed to help you describe your leadership style as you perceive it. Please answer the below items on the separate leader answer sheet. The word "others" may mean your peers, clients, direct reports, supervisors, and/or all of these individuals. If an item is irrelevant, or if you are unsure or do not know the answer, leave the answer blank.

Use the following rating scale:

\begin{tabular}{|c|c|c|c|c|}
\hline 0 & 1 & 2 & 3 & 4 \\
\hline Not at all & Once in a while & Sometimes & Fairly often & $\begin{array}{c}\text { Frequently if not } \\
\text { always }\end{array}$ \\
\hline
\end{tabular}

1. I re-examine critical assumptions to question whether they are appropriate

2. I talk about my most important values and beliefs

3. I seek differing perspectives when solving problems

4. I talk optimistically about the future

5. I instill pride in others for being associated with me

6. I talk enthusiastically about what needs to be accomplished

7. I specify the importance of having a strong sense of purpose

8. I spend time teaching and coaching

9. I go beyond self-interest for the good of the group

10. I treat others as individuals rather than just as a member of a group

11. I act in ways that build others' respect for me

12. I consider the moral and ethical consequences of decisions

13. I keep track of all mistakes

14. I display a sense of power and confidence

15. I articulate a compelling vision of the future

16. I consider an individual as having different needs, abilities, and aspirations from others

17. I get others to look at problems from any different angels

18. I help others to develop their strengths

19. I suggest new ways of looking at how to complete assignments

20. I express confidence that goals will be achieved 
Multifactor Leadership Questionnaire

\section{Leader Answer Sheet}

Important: This answer sheet must be completed \& placed in envelope

Directions: Use this answer sheet to respond to the questions in the MLQ Leader sheet. Judge how frequently each statement fits you. Use the rating scale shown below:

\begin{tabular}{|ccccc|}
\hline 0 & 1 & 2 & 3 & 4 \\
Not at all & Once in a while & Sometimes & Fairly often & $\begin{array}{c}\text { Frequently if not } \\
\text { always }\end{array}$ \\
\hline
\end{tabular}

Please mark your answer as: $\mathrm{O} \mathrm{O} \bullet \mathrm{OO}$

\begin{tabular}{|l|lllll|l|lllll|}
\hline & 0 & 1 & 2 & 3 & 4 & & 0 & 1 & 2 & 3 & 4 \\
\hline $\mathbf{1 .}$ & $\mathrm{O}$ & $\mathrm{O}$ & $\mathrm{O}$ & $\mathrm{O}$ & $\mathrm{O}$ & $\mathbf{1 1 .}$ & $\mathrm{O}$ & $\mathrm{O}$ & $\mathrm{O}$ & $\mathrm{O}$ & $\mathrm{O}$ \\
$\mathbf{3 .}$ & $\mathrm{O}$ & $\mathrm{O}$ & $\mathrm{O}$ & $\mathrm{O}$ & $\mathrm{O}$ & $\mathbf{1 2 .}$ & $\mathrm{O}$ & $\mathrm{O}$ & $\mathrm{O}$ & $\mathrm{O}$ & $\mathrm{O}$ \\
$\mathbf{4 .}$ & $\mathrm{O}$ & $\mathrm{O}$ & $\mathrm{O}$ & $\mathrm{O}$ & $\mathrm{O}$ & $\mathbf{1 3 .}$ & $\mathrm{O}$ & $\mathrm{O}$ & $\mathrm{O}$ & $\mathrm{O}$ & $\mathrm{O}$ \\
$\mathbf{5 .}$ & $\mathrm{O}$ & $\mathrm{O}$ & $\mathrm{O}$ & $\mathrm{O}$ & $\mathrm{O}$ & $\mathbf{1 4 .}$ & $\mathrm{O}$ & $\mathrm{O}$ & $\mathrm{O}$ & $\mathrm{O}$ & $\mathrm{O}$ \\
$\mathbf{6 .}$ & $\mathrm{O}$ & $\mathrm{O}$ & $\mathrm{O}$ & $\mathrm{O}$ & $\mathrm{O}$ & $\mathbf{1 6 .}$ & $\mathrm{O}$ & $\mathrm{O}$ & $\mathrm{O}$ & $\mathrm{O}$ & $\mathrm{O}$ \\
$\mathbf{7 .}$ & $\mathrm{O}$ & $\mathrm{O}$ & $\mathrm{O}$ & $\mathrm{O}$ & $\mathrm{O}$ & $\mathbf{1 7 .}$ & $\mathrm{O}$ & $\mathrm{O}$ & $\mathrm{O}$ & $\mathrm{O}$ & $\mathrm{O}$ \\
$\mathbf{8 .}$ & $\mathrm{O}$ & $\mathrm{O}$ & $\mathrm{O}$ & $\mathrm{O}$ & $\mathrm{O}$ & $\mathbf{1 8 .}$ & $\mathrm{O}$ & $\mathrm{O}$ & $\mathrm{O}$ & $\mathrm{O}$ & $\mathrm{O}$ \\
$\mathbf{9 .}$ & $\mathrm{O}$ & $\mathrm{O}$ & $\mathrm{O}$ & $\mathrm{O}$ & $\mathrm{O}$ & $\mathbf{1 9 .}$ & $\mathrm{O}$ & $\mathrm{O}$ & $\mathrm{O}$ & $\mathrm{O}$ & $\mathrm{O}$ \\
$\mathbf{1 0 .}$ & $\mathrm{O}$ & $\mathrm{O}$ & $\mathrm{O}$ & $\mathrm{O}$ & $\mathrm{O}$ & $\mathbf{2 0 .}$ & $\mathrm{O}$ & $\mathrm{O}$ & $\mathrm{O}$ & $\mathrm{O}$ & $\mathrm{O}$ \\
\hline
\end{tabular}

